\title{
DIVERSITY OF AVFAUNA IN DIFFERENT HABITATS OF THE WASGOMUWA NATIONAL PARK
}

\author{
B Vijitha Perera', U K G K Padmalal2, C N B Bambaradeniya' \\ 'Department of Wildife Conservation, 2Open University of Sri Lanka, \\ 3UCN - The World Conservation Union
}

Wasgomuwa National Park (WNP) is the fourth largest National Park in Sri Lanka. Location of this protected area in between the intermediate zone and dry zone has resulted in a mixture of vegetation types. The main objectives of this study were to determine the avifaunal diversity, distribution, and abundance in different habitats, and provide information for the scientific management of the WNP.

The survey was carried out at 5 different habitats; grassland, scrubland, riverine forest, and tank. Birds were recorded along a line transect covering $150 \times 100 \mathrm{~m}$, with two replicates per habitat. Direct observations as well as bird calls were used to confirm the existence of birds in the study sites. Birds were recorded at three different time frames during the day and each habitat was covered on 21 occasions during the 03 months field study. The species diversity was analyzed under three categories: species richness indices (Margalef's diversity index, Menhinick's index), species abundance model and indices based on the proportional abundances (Shannon diversity index, Simpson's index) of species. The vegetation of each habitat was described by drawing vegetation profiles.

A total of 114 species, belonging to 43 families were recorded from the WNP, during the study period. These included 4 endernic species, and 6 species of nationally threatened birds. The total number of birds recorded in the study habitats was 4752 . The most dominan order was Passerifomes, represented by 41 species in 19 families. Highest number of species was recorded in the riverine habitat and lowest number in the grassland habitat. The highest number of individual birds was recorded in the tank habitat and lowest number of individuals was recorded in the grassland habitat A diurnal variation of the existence of birds was observed in every habitat. Highest number of species and individual birds were recorded in the morning time frame. The Shannon Diversity index was highest in the riverine habitat and lowest in the grassland habitat. There was a significant difference in diversity among study habitats.

This study helped to expand the checklist of birds in the WNP with four new species records. It was revealed that a mosaic of habitats contribute to an increased avifaunal diversity as well as their abundance. Therefore to maintain and enrich the bird diversity in a protected area, the wildlife managers should give high priority to conserve and enhance the habitat diversity.

Proceedings of the Ninth Anmual Forestry and Environment Symposium 2003 of the Department of Forestry and Environmental Science, University of Sri Jayewardenepura, Sri Lanka 